\title{
Efficacy of lower abdominal kinesio taping plus interferential electrical stimulation techniques in the improvement of bowel control in meningomyelocele children
}

\begin{abstract}
Objectives: This work was carried out to investigate the efficacy of lower abdominal kinesio taping plus interferential electrical stimulation techniques in the improvement of bowel control in meningomyelocele children.

Method: 30 children were randomly selected into two groups; group A (lower abdominal kinsotaping plus I.F. current stimulation techniques plus routine traditional physiotherapy program), and group B (routine traditional physiotherapy program only). Children engaged in this study received baseline and post-treatment evaluation using defecation frequency test (DF), visual analog scale (VAS), constipation score system (CSS) to evaluate defecations numbers/week, events of abdominal pain and changes in bowel control. The parents in the two groups A and B were given instructions for the home routine program.

Results: Data analysis was available on the 30 meningomyelocele children participated in the study. The difference between pre and post-treatment results was significant in the study group in all variables. By comparison of the two groups in DF at post-treatment, there was a suggestive promotion in defecation frequency (DF) $(\mathrm{p}<.05)$. By comparison of the two groups in abdominal pain at post-treatment, there was a significant decrease in abdominal pain measured $(\mathrm{p}<.05)$. By comparison of the two groups in constipation score system at post-treatment, there was a suggestive promotion in bowel control $(\mathrm{p}<.05)$.

Conclusion: According to the results of this study, it can be concluded that the combined effect of lower abdominal kinesio taping plus interferential electrical stimulation techniques in addition to routine traditional physiotherapy program was better than routine traditional physiotherapy program along and can be recommended in improvement bowel control in meningomyelocele children.
\end{abstract}

Keywords: interferential electric stimulation, kinesio tapping,bowel control, meningomyelocele

\section{Introduction}

The bowel is controlled via parasympathetic, sympathetic, sacral motor and sensory nerves besides enteric nervous control which plays an essential act in myelomeningocele in which the bowel nervous control is interrupted. The enteric nervous control has an important capacity in maintaining some intestinal motility which prevents the bowel from being automatic as in automatic bladder. ${ }^{1}$

In myelomeningocele, there is an interruption of the pathway of bowel control via loss of the message given by pressured rectum which normally informs brain for emptying the rectum via an order from the brain to relax the external anal sphincter. but the rectum in myelomeningocele is weak and stretched losing the sensory perception mechanism which leads to accumulation of the waste in rectum prolonged duration lead to constipation. ${ }^{2}$

Constipation in myelomeningocele leads to increase of the abdominal contents which press upward the lung leading to limitation of costovertebral joints and decrease of the thorax expansion with difficulty in breathing affecting on posture. besides hindering of the daily living activities. ${ }^{3,4}$

Deep electrical stimulation by using interferential current stimulates the skin nerve fibers which can lead to facilitation of the parasympathetic nerve fibers and modulate the sacral reflexes controlling the bowel movment. ${ }^{5,6}$
Volume 7 Issue 4 - 2017

\author{
Ahmed M Azam \\ Department of physiotherapy for developmental disturbance \\ and pediatric surgery, Faculty of physical therapy, Cairo \\ University, Egypt
}

Correspondence: Ahmed M.Azam, Department of Physiotherapy for Developmental Disturbance and Pediatric Surgery, Faculty of physical therapy, Cairo University, Giza, Egypt, Tel 967000000000, Email prof.ahmedazzam@yahoo.com

Received: October 24, 2017 | Published: December 21, 2017

\section{Materials and methods}

\section{Subject}

30 children from both sexes with post-operative reduction meningomyelocele children were randomly selected, aged 6 to 10 years at the point of recruitment because the children in this age who can understand the research work principles and rules were included in the study. Body weight, height and hand dominance, type of involvement, level of ambulation were recorded for each subject. The excluded criteria include children who had previous chest or abdominal surgery and shunt operation for hydrocephalus.

Children were randomized into the experimental group (A) received the IF (interferential current stimulation) plus lower abdominal and sacral kinsotaping in addition to routine traditional physiotherapy program and control group (B) who received routine traditional physiotherapy program only.

\section{Outcome measurement}

I. Defecation frequency (number of defecations/week): lower than 3 times /week consider chronic constipation. The Main goal was to investigate the elevation in defecation frequency further than 3 times per week.

II. Visual analog scale: for detecting and following the degree of events of abdominal pain and severity of constipation/week. It 
consists of 10 C.M. line starting with 0 degrees which means no constipation and 10 degrees mean sever constipation ${ }^{7}$.

III. Constipation score questionnaire: it consists of 8 items(Frequency of bowel movements, crisis: painful emptying effort, feeling incomplete evacuation, abdominal pain, minutes in bathroom per attempt, type of assistance, unsuccessful attempts for emptying all the day and night and the time of constipation) rating scale from 0 (normal) to 30 (severe constipation). A cut-off score of 15 suggests constipation. It was performed before starting the treatment and after 3 months of treatment.

\section{Intervention}

Interferential electric stimulation session 60 minutes at the level of sensory stimulation decrease than $20 \mathrm{~mA}$, sweep frequency were 5-10 $\mathrm{Hz}$, duration of 200 micosecond and time of repetition was 6 seconds) were conducted three times weekly with changing of tapping every 48 $\mathrm{H}$ for 12 weeks in a physiotherapy treatment room after the routine regular physiotherapy program session which lasts for30 minutes for group (A) and the routine regular physiotherapy program session only for the group (B).

\section{The Ist technique of Interferential (IF)}

The individual-based interferential electric stimulation sessions of 60 minutes consists of 2 parts first 30 minutes: abdominal electrodes were located under the costal levels bilaterally on the lateral sides one electrode from each channel while the other two electrodes were located crossly between levels of thoracic 12 and lumbar 4 bilaterally on lateral sides at sensory levels with no visible nor palpable contraction.

\section{The 2nd technique of interferential stimulation}

The second part lasts for another 30 minutes by placement of the abdominal two electrodes at supra pubic levels bilaterally at lateral sides, while other two electrodes crossly placed at sacral dimple bilaterally at sensory levels with neither visible nor palpable contraction $^{5,9}$ (Figure 1).

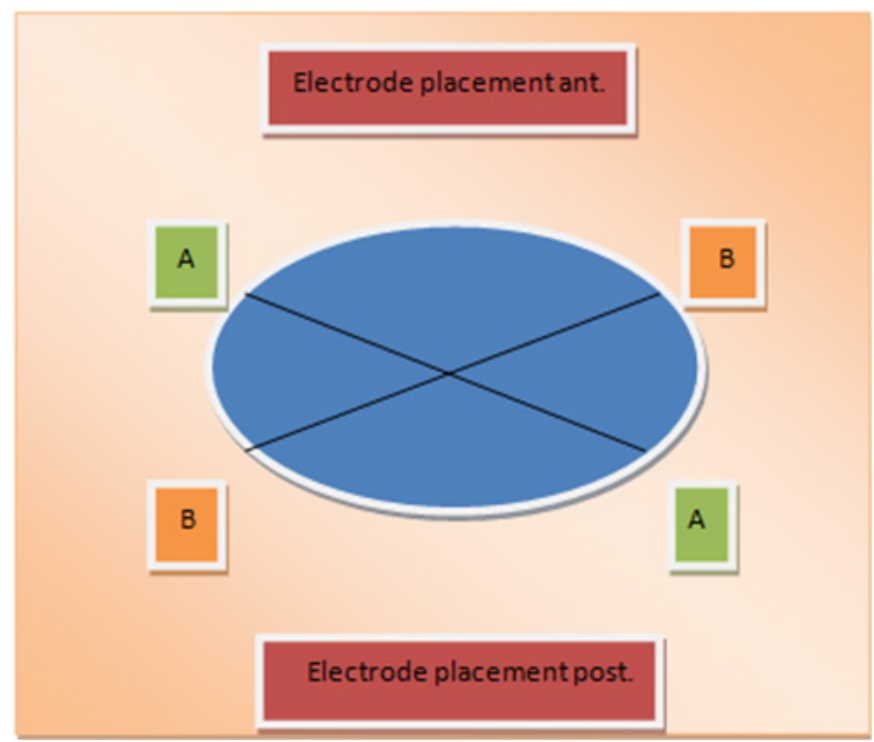

Figure I Electrodes placement of interferential electric stimulation

\section{Kinesio taping}

Taping was applied on lower abdomen between RT ASIS and LT ASIS without stretching of both ends with $25-50 \%$ stretch to the residual taping while taping was applied on lumbosacral area in star technique with $25-50 \%$ stretch plus routine traditional physiotherapy program. $^{10}$

Children in the two groups were exposed to home routine program for the 12 weeks treatment period as the following:

Home routine program for meningomyelocele children with instruction to parents:

a. Using foot and hand drill as a support for helping bearing down.

b. Diet control by using a high amount of fruit, a diet containing fibers and water

c. Improve coordination between muscles of the abdomen and of the pelvic floor.

d. Staying after each meal 5minutes in bath room keeping knees higher than hips as a toilet training. ${ }^{11}$

e. Parents should observe which food has an accident effect on the bowel movement

f. Making the life as a routine as possible this may improve bowel control. ${ }^{2}$

\section{Routine regular physiotherapy program for the two groups include}

i. Proprioceptive training via manual approximation in all joint direction with fast un rhythmic technique besides weight bearing ex. as a static proprioceptive training

ii. Quick stretching for distal muscles, compression on bony prominence, triggering of mass flexion via stimulate flexor withdrawal reflex and forced flexion to the toes, rapping on a shaft of the tibia, stimulate tonic vibration reflex by vibrator on the musculotendinous junction.

iii. Activation of contractile muscle property via tactile stimulation(scratch, taping, squeeze, rapping, pressure and painful stimuli)followed by movement

iv. Facilitation of postural reaction(righting-equilibrium and protective reaction training)

v. Facilitation of mile stones as sitting, standing, walking

vi. Facilitation of activity of daily living activities as feeding, dressing, and toileting

vii. Facilitation of hand function as grasping, voluntary release, eye- hand coordination, reaching, bilateral hand use and hand manipulative skills

viii. Graduated active exercise for trunk muscles(abdominal, erector spinae and lateral flexors)

ix. Strengthing exercises for shoulder depressors and elbow extensors

x. Gait training in closed environment by assisted devices

xi. Faradic stimulation to lower limb muscles of antigravity (both tibialis anterior-both quadriceps, both glutei maximus and both glutei medius)

xii. Orthoses:

a. Static orthoses by using night ankle foot orthoses to prevent tendo-achillis tightness 
b. Dynamic orthoses by using hip-knee -ankle- foot orthoses with the pelvic band and elbow crutches

\section{Result}

\section{Patients characteristics}

Table 1 shows the patients characteristics. There were 17 boys $(56,66 \%)$ and 13 girls $(43.33 \%)$. and in regards right-hand dominance reported in 14 patients $(46,66 \%)$, and also 16 patients $(53.33 \%)$ were left-hand dominance. There was no expressive difference between the two groups regarding age $(p=0.9)$, regarding sex $(p=0.72)$ and in regards hand dominance $(\mathrm{p}=0.48)$.

\section{Changes in defecation frequency}

Mean test scores and SD for the two groups are demonstrated in table 2. The mean record of DF variable in the two groups (assessed by the number of defecations/week) at baseline measurement (pretreatment) was insignificant $(\mathrm{p}>0.05)$ while study group had an expressive enhancement in DF (post-treatment) $(p<0.05)$. The average improvement of DF variable tended to be significant in the experimental group ( $2.40 \pm 0.63$ VS $2.67 \pm 0.90, \mathrm{p}=0.04)$ while insignificant result in the treatment group $(2.47 \pm 0.52 \mathrm{VS} 2.60 \pm 0.63$, $\mathrm{p}=0.16$ ). The percentage of improvement of DF was $11.25 \%$ in the study group while was $5.2 \%$ in control group

Table I Patients' characteristics

\begin{tabular}{|c|c|c|c|}
\hline Variables & Study group $N=15$ & Control groupN= 15 & P-value \\
\hline Age & $8 \pm 1.46$ & $7.93 \pm 1.39$ & 0.9 \\
\hline \multicolumn{4}{|l|}{ Sex N\% } \\
\hline $\begin{array}{l}\text { Boys } \\
\text { Girls }\end{array}$ & $\begin{array}{l}9(60 \%) \\
6(40 \%)\end{array}$ & $\begin{array}{l}8(53.33 \%) \\
7(46.66 \%)\end{array}$ & 0.72 \\
\hline \multicolumn{4}{|c|}{ Hand dominanceN\% } \\
\hline $\begin{array}{l}\text { Right } \\
\text { Left }\end{array}$ & $\begin{array}{l}8(53.33) \\
7(46.66)\end{array}$ & $\begin{array}{l}6(40 \%) \\
9(60 \%)\end{array}$ & 0.48 \\
\hline
\end{tabular}

Table 2 The average test of defecation frequency variable in the two groups

\begin{tabular}{llll}
\hline $\begin{array}{l}\text { Defecation Frequency } \\
\text { Variable }\end{array}$ & $\begin{array}{l}\text { Study Group } \\
\text { Mean } \pm \text { SD }\end{array}$ & $\begin{array}{l}\text { Control Group P-Value } \\
\text { Mean } \pm \text { SD }\end{array}$ & (within groups) \\
\hline Pre-treatment & $2.40 \pm 0.63$ & $2.47 \pm 0.52$ & 0.75 \\
Post-treatment & $2.67 \pm 0.90$ & $2.60 \pm 0.63$ & 0.82 \\
Improvment\% & $11.25 \%$ & $5.2 \%$ & 0.26 \\
P-value (within groups) & 0.04 & 0.16 & \\
\hline
\end{tabular}

\section{Events of abdominal pain variables}

Mean test scores and SD for the two groups are demonstrated in table 3. The mean record of events of abdominal pain variables in the two groups (assessed by visual analog scale) at baseline measurement (pre-treatment) was insignificant $(\mathrm{p}>0.05)$. while study group had an expressive enhancement in events of abdominal pain variables (posttreatment $)(p<0.05)$. The average improvement of events of abdominal pain variables tended to be significant in the experimental group $(6.47 \pm 1.51$ VS $6.00 \pm 1.56, p=.03)$ while insignificant result in the treatment group $(5.80 \pm 1.78$ VS $5.67 \pm 1.84, p=0.16)$. The percentage of improvement of events of abdominal pain variable was $7.26 \%$ in the experimental group while was $2.2 \%$ in treatment group.

\section{Constipation sore system (CSS) variable}

Mean test scores and SD for the two groups are demonstrated in table 4. The mean record of CSS variables in the two groups (assessed by Constipation sore system (CSS) questionnaire) at baseline measurement (pre-treatment) was insignificant $(p>0.05)$. while study group had an expressive enhancement in Constipation score system variables (post-treatment) $(\mathrm{p}<0.05)$. The average improvement of Constipation sore system variables tended to be significant in the experimental $(22.20 \pm 3.26$ VS $21.40 \pm 2.59, \mathrm{p}=0.03)$ while insignificant result in the treatment group $(22.80 \pm 2.93$ VS $22,60 \pm 2.69, \mathrm{p}=0.42)$. The percentage of improvement of CSS variable was $3.6 \%$ in the study group while was. $88 \%$ in control group.

Table 3 The average test of events abdominal pain variable in the two groups

\begin{tabular}{llll}
\hline $\begin{array}{l}\text { Episodes of Abdominal } \\
\text { Pain Variable }\end{array}$ & $\begin{array}{l}\text { Study Group } \\
\text { Mean } \pm \text { SD }\end{array}$ & $\begin{array}{l}\text { Control Group P-Value } \\
\text { Mean } \pm \text { SD }\end{array}$ & (within groups) \\
\hline Pre-treatment & $6.47 \pm 1.5 \mathrm{I}$ & $5.80 \pm 1.78$ & 0.28 \\
Post-treatment & $6.00 \pm 1.56$ & $5.67 \pm 1.84$ & 0.46 \\
Improvment\% & $7.26 \%$ & $2.2 \%$ & 0.55 \\
P-value (within groups) & .03 & 0.16 & \\
\hline
\end{tabular}

Table 4 The average test of Constipation sore system variable in the two groups

\begin{tabular}{llll}
\hline $\begin{array}{l}\text { Constipation Sore } \\
\text { System Variable }\end{array}$ & $\begin{array}{l}\text { Study Group } \\
\text { Mean } \pm \text { SD }\end{array}$ & $\begin{array}{l}\text { Control Group P-Value } \\
\text { Mean } \pm \text { SD }\end{array}$ & (within groups) \\
\hline Pre-treatment & $22.20 \pm 3.26$ & $22.80 \pm 2.93$ & 0.6 \\
Post-treatment & $21.40 \pm 2.59$ & $22,60 \pm 2.69$ & 0.16 \\
Improvment\% & $3.6 \%$ & $.88 \%$ & 0.06 \\
P-value (within groups) & 0.03 & 0.42 & \\
\hline
\end{tabular}

\section{Discussion}

The outcomes of the present study are consistent with the results of Chase et al., ${ }^{5}$ who found that IF electrical stimulation applied on abdominal muscles, produce $50 \%$ improvement in controlling constipation symptoms in children. Moreover, a study by Kajbafzadeh et al., ${ }^{6}$ who reported that, Although IF electrical stimulation did not apply on pelvic floor muscles directly, modulation of sacral reflexes occurs improving the bowel control after using IF stimulation technique.

Interferential electric stimulation is broadly handling in the treatment of bowel and bladder disturbance to meningomyelocele children. Activation of pelvic floor muscles with Facilitation of pudendal afferent nerve fibers via IF activate hypo gastric efferent's and inhibit pelvic efferent to control sacral reflexes and improved bladder contraction. ${ }^{12}$

Bowel nervous control is occurred by 3 main underlying mechanisms first one is the enteric nervous system which forms an extensive neural network inside GIT. It can work autonomously if interruption occurs from CNS insults but less efficient. It contains great numbers of neurons which form two plexus the myenteric plexus which control motility of gut and secretomotor function besides submucosal plexus which organize the secretions, blood flow, and transport through the cells and it also contains important neurotransmitter as serotonin, acetylcholine and GABA. ${ }^{13}$

The second mechanism includes the parasympathetic fibers supply to GIT via facilitating peristalsis movement of the intestine. It is motor to descending colon, rectum and internal anal sphincter and sensory to the intestine for detecting the perception and it also organizes secretions and relaxes internal anal sphincter besides sympathetic autonomic supply reduce the gut activity and facilitate internal anal sphincter. 
The third mechanism includes the somatic neve supply. The pudendal nerve act as motor fibers to the external anal sphincter, puborectalis and other pelvic floor muscles which act together to control defecation by contraction to maintain continence and relaxation to facilitate defecation and it also act sensory to pelvic floor muscles and anal sphincter ${ }^{14}$ (Figure 2).

Application of kinesio taping on the lower abdomen and sacral area stimulate cutaneous mechanoreceptors as the free nerve ending, pacini and Ruffini receptors present in a great amount in the fascia to give the CNS information about pain and position. When they are stimulated by kinesio taping they decrease the sympathetic nervous system activity and this leads to increase parasympathetic activity which can improve bowel control. ${ }^{18}$ (Figures $3 \& 4$ ).

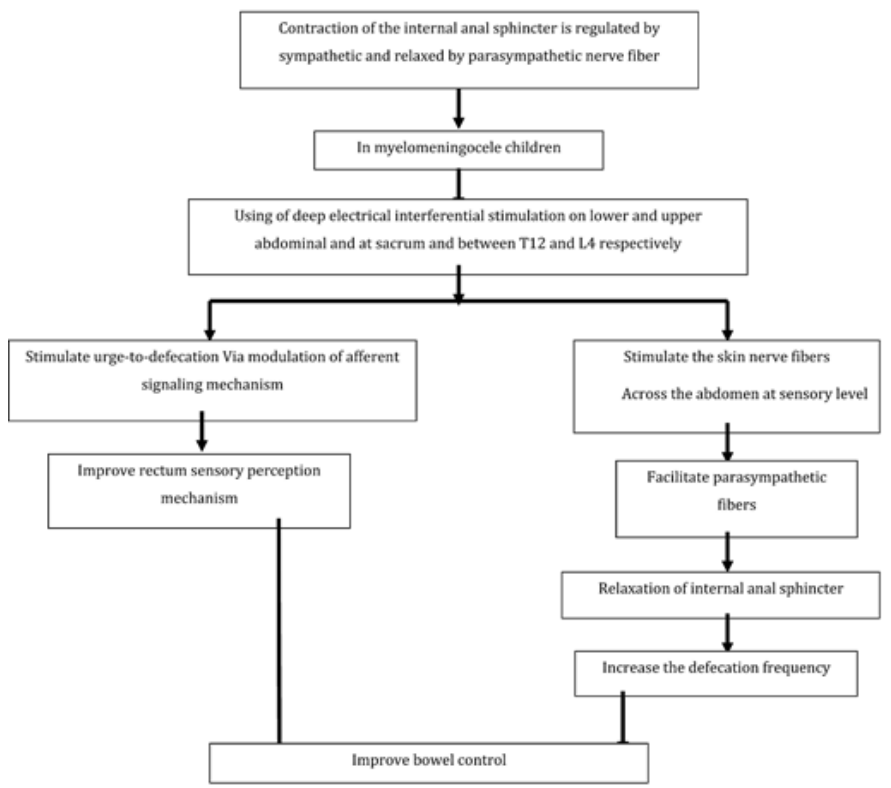

Figure 2 Underlying mechanisms of interferential electrical stimulation ${ }^{5,15-17}$

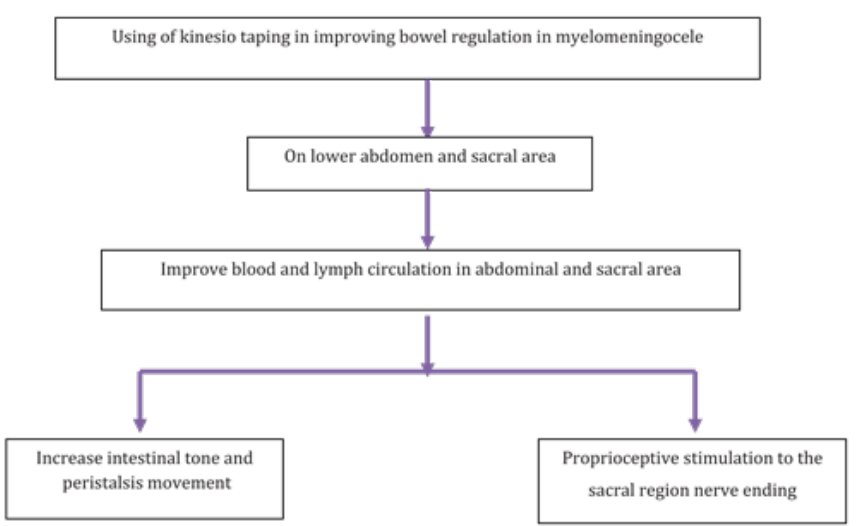

Figure 3 Underlying mechanism of kinesio taping in bowel control. ${ }^{19-26}$

\section{Conclusion}

According to the outcomes of this study, it can be terminated that the combined effect of lower abdominal kinesio taping plus I.F. electrical stimulation techniques besides routine regular physiotherapy program could be recommended in improvement bowel regulation in meningomyelocele children.

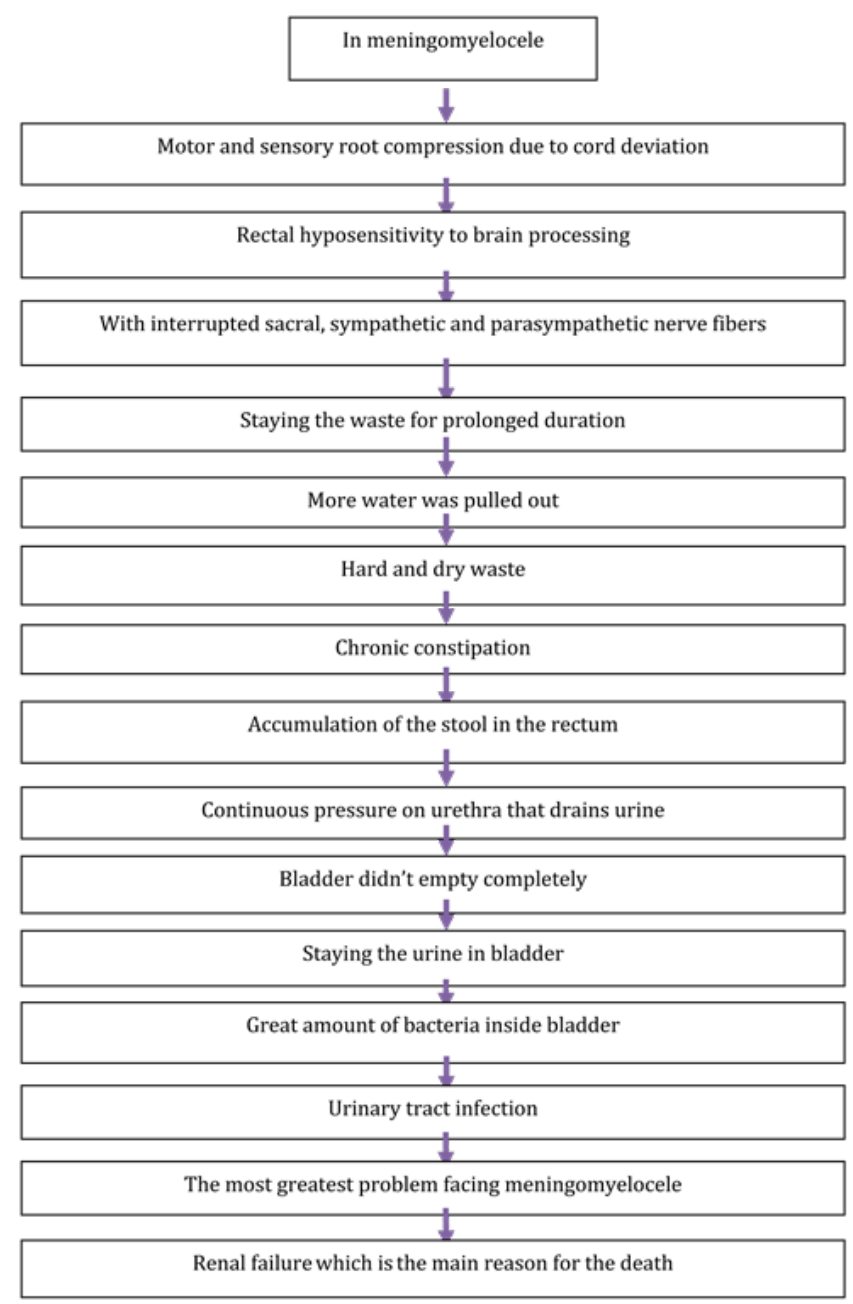

Figure 4 Complications of bowel disturbance in myelomeningocele..$^{2,27-29}$

\section{Acknowledgements}

None.

\section{Conflicts of interest}

None.

\section{Funding}

None.

\section{References}

1. Stiens SA, Bergman SB, Goetz LL. Neurogenic bowel dysfunction after spinal cord injury: clinical evaluation and rehabilitative management Archives of Physical Medicine and Rehabilitation. 1997;78(3):86-102.

2. Jaskowiak MS. Bowel Control in Children with Spinal Cord Injuries and Spina Bifida. The Emily Center at Phoenix Children's Hospital 1919 East Thomas Road Phoenix. 2005.

3. Sparacio J. The Effects of Seating on Respiratory Function. Seventeenth International Seating Symposium. 2001;22-24

4. Mills JL, Konkin DE, Milner R. Long-term bowel function and quality of life in children with Hirschsprung's disease. J Pediatr Surg. 2008;43(5):899-905. 
5. Chase J, Robertson VJ, Southwell B. Pilot study using transcutaneous electrical stimulation (interferential current) to treat chronic treatmentresistant constipation and soiling in children. $J$ Gastroenterol Hepatol. 2005;20(7):1054-1061.

6. Kajbafzadeh AM, Sharifi,R L, Nejat F. Transcutaneous interferential electrical stimulation for management of neurogenic bowel dysfunction in children with myelomeningocele. Int $J$ Colorectal Dis. 2012;27(4):453-458.

7. Ojetti V, Bruno G, Paolucci V. The prevalence of small intestinal bacterial overgrowth and methane production in patients with myelomeningocele and constipation. Spinal Cord. 2014; 52(1):61-64.

8. Agachan F, Chen T, Pfeifer J. A constipation scoring system to simplify evaluation and management of constipated patients. Dis Colon Rectum. 1996;39(6):681-685.

9. Yik YI, Ismail KA, Hutson JM, et al. Home transcutaneous electrical stimulation to treat children with slow-transit constipation. $J$ Pediatr Surg. 2012;47(6):1285-1290.

10. Orhan C, Kara OK, Kaya S, et al. The effects of connective tissue manipulation and Kinesio Taping on chronic constipation in children with cerebral palsy: a randomized controlled trial Article in Disability and Rehabilitation. 2016;40(1):10-20.

11. Seyedian SL, Rad LS, Manouchehri N, et al. A comparative study of transcutaneous interferential electrical stimulation plus behavioral therapy and behavioral therapy alone on constipation in postoperative Hirschsprung disease children. 2017;52(1):177-183.

12. Appell RA. Electrical stimulation for the treatment of urinary incontinence. Urology. 1998;51(2):24-26.

13. Goyal RK, Hirano I. The enteric nervous system. $N$ Engl J Med. $1996 ; 335(3): 215$

14. Dubrovsky B, Filipini D. Neurobiological aspects of the pelvic floor muscles involved in defecation. Neurosci Biobehav Rev. 1990;14(2):157-168.

15. Moore K, Dalley A, Ague A. Clinically oriented anatomy. (6th edn), Lippincott Williams \& Wilkins, Washington, USA. 2009.

16. Jung KW, Yang DH, Yoon IJ. Electrical stimulation therapy in chronic functional constipation: five years' experience in patients refractory to biofeedback therapy and with rectal hyposensitivity. $J$ Neurogastroenterol Motil. 2013;19(3):366-373.
17. Collins B, Norton C, Maeda Y. Percutaneous tibial nerve stimulation for slow transit constipation: a pilot study. Colorectal Dis. 2012;14(4):165-170.

18. Callaghan MJ, Selfe J, Bagley PJ, et al. The effects of patellar taping on knee joint proprioception. J. Athl. Train. 2002;37(1):19-24.

19. Morris D, Jones D, Ryan H. The clinical effects of KinesioVR tex taping: a systematic review. Physiother Theory Pract. 2013;29(4):259-270.

20. Lim EC, Tay MG. Kinesio taping in musculoskeletal pain and Disability . Br J Sports Med. 2015; 49(24):1558-1566.

21. Iosa M. The application of Kinesio taping in children with cerebral palsy. Dev Med Child Neurol. 2015;57(1):11-12.

22. Costa CS, Rodrigues FS, Leal FM. Pilot study: investigating. 2013;16(2):121-128

23. Kaya OK, Atasavun US, Turker D. The effects of Kinesio taping on body functions and activity in unilateral spastic cerebral palsy: a single-blind randomized controlled trial. Dev Med Child Neurol. 2015;57(1):81-88.

24. Mazzone S, Serafini A, Iosa M. Functional taping applied to upper limb of children with hemiplegic cerebral palsy: a pilot study. Neuropediatrics. 2011;42(6):249-253.

25. Simsek TT, Turkucuoglu B, Cokal N. The effects of Kinesio(R) taping on sitting posture, functional independence and gross motor function in children with cerebral palsy. Disabil Rehabil. 2011;33(22):2058-2063.

26. Kase K, Wallis J, Kase T. Clinical therapeutic applications of the Kinesio taping method. 2nd ed. Tokyo: Ken Ikai Co Ltd. 2003;4(2):33-38.

27. Carrington EV, Knowles $\mathrm{CH}$. The influence of sacral nerve stimulation on anorectal dysfunction. Colorectal Dis. 2011;13(2):5-9.

28. Burgell RE, Lelic D, Carrington EV. Assessment of rectal afferent neuronal function and brain activity in patients with constipation and rectal hyposensitivity. Neurogastroenterol Motil. 2013; 25(3):260-267.

29. Carrington EV, Evers J, Grossi U. A systematic review of sacral nerve stimulation mechanisms in the treatment of fecal incontinence and constipation. Neurogastroenterol Motil. 2014;26(9):1222-1237. 